\title{
Science and organization in open-sea research: the plankton
}

\author{
K. Banse \\ School of Oceanography, WB-10, University of Washington; Seattle, WA 98195, U. S. A.
}

\begin{abstract}
Looking forward on this occasion, rather than reviewing the past 100 years, it appears that 100 years hence, we will have to manage the environment worldwide like a global garden. How will the ecological knowledge necessary for sound management be acquired? Drawing especially on concepts about the plankton of the open North Sea and on unresolved issues of understanding, questions will be raised about research direction and organization that will need to be answered long before the next 100 years have passed.
\end{abstract}

\section{INTRODUCTION}

At anniversaries, we should look back to see what we might learn from the past; we also should take stock of where we stand and where we might or must go. I would like to use the occasion primarily to address the present and the future. After introducing the subject by speaking as a scientifically alert citizen, I will make an historical excursion, elaborate on conceptual issues of plankton research in the open sea, and close, by venturing some remarks about the institutional framework in which we will have to work in the foreseeable future.

“A century from now humanity will live in a managed - or mismanaged - global garden" (Steele et al., 1989). Presently, we worry about what to do about overfishing, ponder possible sub-lethal effects of oil or sewage discharge into the coastal oceans, and are scared by red and brown tides; we discuss the necessity to save some of the tropical forests; we are beginning to control emission of "greenhouse gases" into the atmosphere; and we struggle to calculate how fast and by how much the climate will become warmer with and without such controls. A century from now, these separate concerns will have been integrated into a single management system because of objective needs, but perhaps also because of broad intolerance of the mismanagement of nature. Obviously, the running of such a controlled system will require massive, continuous data-collecting or monitoring, which presumably will be largely automated. Our great-grand-children, therefore, "will live on a wired earth". (Steele et al., 1989). Using the data so gathered, however, will demand massive improvements in scientific concepts, and this improvement is already the task for the present generation. It is a challenge that goes well beyond marine biology.

The development of new concepts requires good training of good minds, as has always been the case. For the present and future task of materially improving ecological understanding, however, we also clearly need more observations and experiments now: 
the new biological-oceanographic concepts need to be developed on the basis of facts. Do we presently gather the facts in an institutionally efficient manner, or do we too often polish nice little stones that may or may not fit into the big mosaic?

\section{PLANKTON IN THE OPEN SEA}

I will develop principal research issues using the plankton as an example. The term plankton comprises plants, animals, and bacteria - of microscopic to barely-visible size that drift with the currents, in contrast to adult fishes and whales and to the bottom-living plants, animals, and bacteria. The principal tool for collecting (at least the larger forms) is the plankton net.

\section{Johannes Müller and his plankton net}

Why speak about plankton on a rocky island, a mecca for many researchers of bottom life since the 1830's? It so happens that the use of the plankton net was popularized by Johannes Müller, who visited Helgoland in 1845, 1846, and 1854 (Bückmann, 1959; much of the following information taken from Heuss, 1940). Müller, a member of the Medical Faculty of the University of Berlin, was the founder of modern, experimental physiology, as well as of histological pathology. During the last two decades of his life, the 1840's and 1850's, however, he spent much time with comparative anatomy and what subsequently became zoology. For example, in 1849 he published on the larvae and metamorphosis of the echinoderms, based largely on observations on Helgoland and at Kristineberg (Sweden).

After the 1840 's, many zoologists visited sea-shores, which by that time began to be easily reached because of the completion of trans-continental railroads. In 1859, Darwin provided the comprehensive theory for the study of invertebrates, Haeckel soon after claimed that ontogeny recapitulates phylogeny, the introduction of the microtome in the mid-1860's further advanced research, and more zoologists visited the sea-shores. It was a tremendously exciting period in the life sciences because of the new and unifying conceptual framework.

At the time, zoology consisted largely of classification and anatomy, for which only field collecting was required. To the dismay of the innkeepers, much of the sorting and fixing of the collections was done in the guests' wash-basins. As noted, however, by Anton Dohrn in a programmatic paper of 1872, "Der gegenwärtige Stand der Zoologie und die Gründung zoologischer Stationen" (The Present State of Zoology and the Establishment of Zoological Stations), the more basic flaw of this practice was that the scientific study of the 'struggle for existence' and 'survival of the fittest' - the order of the day - would also require live observations, i. e. aquaria.

The marine stations that were subsequently established could not rely on fishermen for collecting specimens and therefore had to acquire their own boats. The first steamer (1877) of the mother of all stations, at Naples, was named "Johannes Müller", and not "Linnaeus", "Cuvier", or "Darwin", which illuminates the role attributed at the time to Müller - also in respect to marine research. This vignette brings us back to Helgoland and its contribution to marine-biological research. The station here, of course, was a late arrival, as the island only came to Germany in 1890 , but from the very outset, one of its 
many distinctions was to have been christened Biologische Anstalt. In contrast, most of the other stations carry only 'Zoological' in their names. Ever since, "die Anstalt" has lived up to the obligation implied by the name.

\section{The plankton community}

The guiding thread through the following is (1) the plankton of the open sea is among the players in the "greenhouse warming", (2) after more than a century of quantitative plankton research, we still do not understand basic issues, i.e. "how the system works", and still cannot predict the effect of, say, a certain change of sea surface temperature on the organisms and the feedback from them to the ocean-atmosphere system, and $(3$, in later chapters) the coastal plankton is more easily studied than offshore communities.

Apart from the physical interactions of the sea with the atmosphere (exchange and transport of heat; moisture; cycles of release and absorption of $\mathrm{O}_{2}$ and $\mathrm{CO}_{2}$ owing to seasonal temperature changes), the ocean plays a role in maintaining or changing the global climate by naturally emitting biologically produced "greenhouse gases" (e.g. $\mathrm{N}_{2} \mathrm{O}$ ), by taking up human-caused $\mathrm{CO}_{2}$, and by releasing the gaseous DMS (see below). These processes involve organisms that are likely to be affected by climate shifts, but that in turn may alter the rate or direction of gas exchange that an abiotic ocean would assume, as partly reviewed in Longhurst $\left(1991\right.$; for $\mathrm{CO}_{2}$, cf. Garçon et al., 1992). Regarding the recently discovered role of dimethylsulfide (DMS), some (but only some!) phytoplankton species release dimethyl-sulfoniopropionate (e. g. when being eaten) that is later transformed into DMS. The gas can escape into the air, be oxidized to sulfate, with water vapour form clouds, and thus affect the heat balance of the earth (Charlson et al., 1987; Malin et al., 1992). The global DMS emission depends in high latitudes on the area covered by sea ice, and elsewhere on the kind, amount, and activity of DMS-producing phytoplankters and the animals that graze on them, thereby affecting their concentrations. The effects of weather and climate on water temperature, which ultimately result also from DMS' feed back to the plankton community - including its species composition - which again may alter the gas exchange (including $\mathrm{O}_{2}, \mathrm{CO}_{2}$, and $\mathrm{N}_{2} \mathrm{O}$ ) between water and air. It is because of these interactions between part of the biota and climate that an understanding of geographic distribution, not only of total biomass but of individual species, will be required in the near future - a field that was originally the domain of descriptively-working taxonomists.

The plankton community is introduced here by a sketch of the ecosystem of the upper water column in the North Sea that is centred around the herring (Fig. 1; the scheme was first presented by Hardy, 1924). It is especially appropriate to use this early figure on the present occasion because fisheries research was one of the missions assigned to the Biologische Anstalt at the time of its founding. The scheme concerns feeding relations. Who eats whom depends a lot on size and, with respect to most plankton-feeding fishes like herring and mackerel, also on visibility of the prey. One of the principal points Hardy wanted to make was that a very young (i.e., very small) fish plays a different role from that of a big fish. In the North Sea, for example, the larval herring may be preyed upon by arrow worms although the latter are prey for large herring. Figure 1 is somewhat confusing because, in contrast to the original (Hardy, 


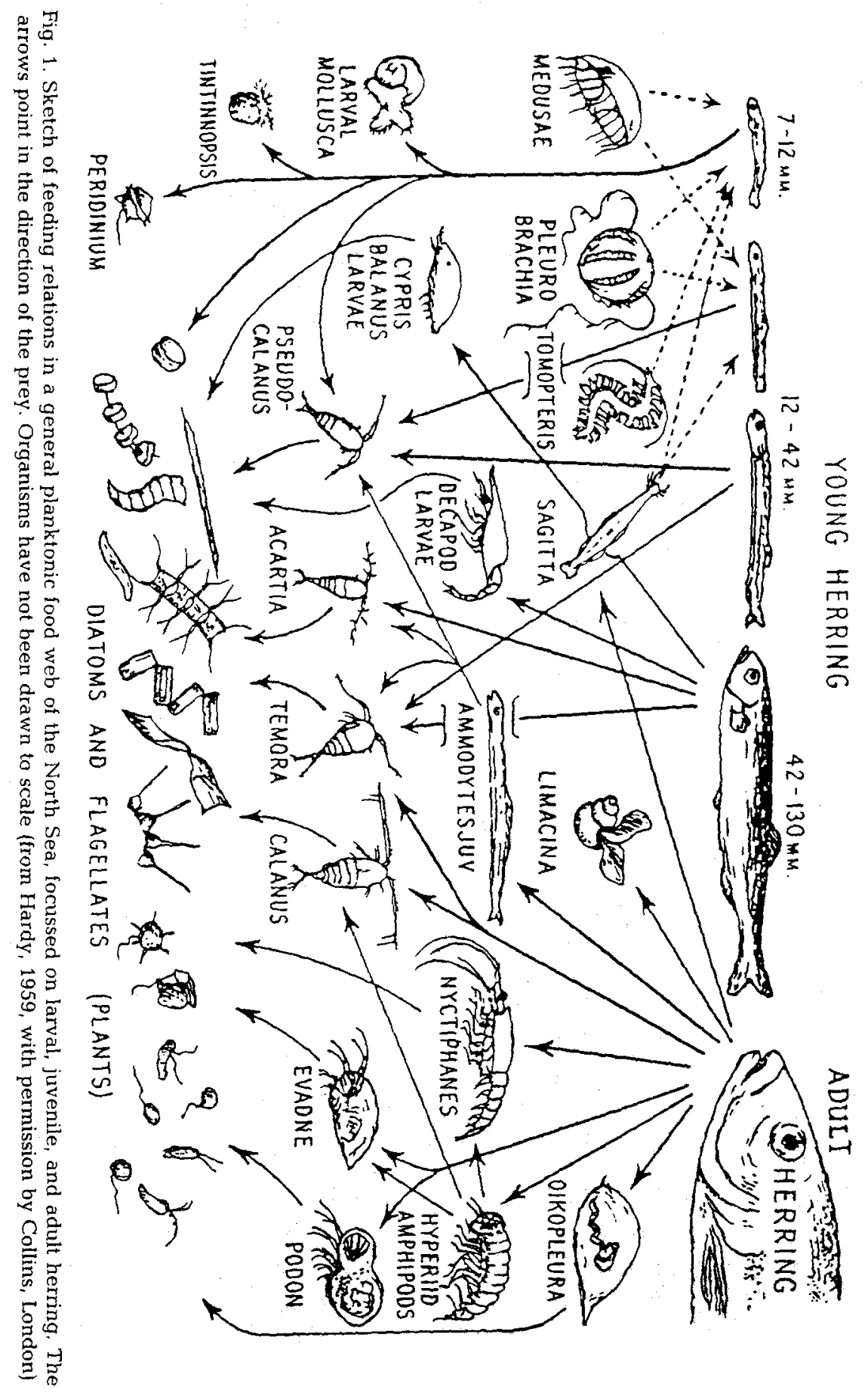


1924), it does not indicate the relative importance of the depicted species and connecting strands, which may change with the season. For example, for 2-3 spring months adult herrings in the North Sea focus on juvenile sandlance (or sand eel, Ammodytes spp.; Wyatt, 1976). On the other hand, the picture is vastly simplified because of the omission of bacteria and almost all developmental stages of the zooplankton. For the latter, the same principles hold as for the roles of larval versus adult herring. Also lacking are the "jellyfish" and the bony fishes, such as adult sand eels, which compete with the herring for the same food, as well as the predators of the herring, including fishermen.

The understanding of the mechanisms that maintain the composition or structure of this or any other marine plankton community with respect to kind of species, abundance relative to each other, and absolute concentrations, is as yet elusive. No species occurs as widely as its innate physiological capacity would allow. Each has to strike a balance between reproduction (rate of cell division for unicellular species, or number of eggs times developmental rates for multicellular forms, as modified by the environment [including competition] and nutrition) and rate of mortality (mostly from predators and physical processes like mixing). For each species, the balance varies among regions, and within regions, with seasons and often also with years. The supreme challenge for contemporary ecology, be it divorced from practical questions or concerned with pests (including red and brown tides) or fisheries management, is to proceed beyond such general rules and understand cases quantitatively, so that predictions can be made.

\section{A simplified foodweb of the North Sea plankton and the underlying theory}

The relations among the organisms in Figure 1, although simplified, are too complex to be currently amenable to experimental or mathematical treatments. We know far too little of the natural history of most of the main players to formulate a mathematical model that calculates their population dynamics within a complete food web. This is so, in spite of more than 100 years of work at numerous marine stations, universities, and government laboratories. In addition to insufficient knowledge about natural history, we are plagued by questions, such as the proper temporal and spatial scales in collecting and modelling, or the issue of deterministic vs. stochastic (chance) processes (e.g. animal swarms). These questions pose major challenges in themselves.

Figure 2 is a more practical rendition of a planktonic food web as found in the North Sea that was introduced 16 years ago at another symposium at Helgoland. It depicts a theory of interrelated, testable hypotheses and is more complete than Figure 1, in as much as nutrients and physical processes are recognized. The focus is on feeding ty pes, e.g. the visually plankton-feeding fish, the "filter-feeding" large crustacean eating large phytoplankton (middle right-hand, with its larvae in the lower middle of the left-hand column consuming small phytoplankton), the non-visually feeding invertebrate predators and their young (upper left; others, like medusae or camivorous crustaceans, are not depicted), and so on. The theory addresses the major mechanisms that control the structure of a community. Among the candidate controls are (a) the abiotic environment (e.g. weather, nutrients; so-called bottom-up control) and (b) predation (so-called topdown control). The two control mechanisms are not mutually exclusive, and in some regions might change place with seasons.

As explained by Landry (1977), who leaned towards bottom-up control, this mechan- 


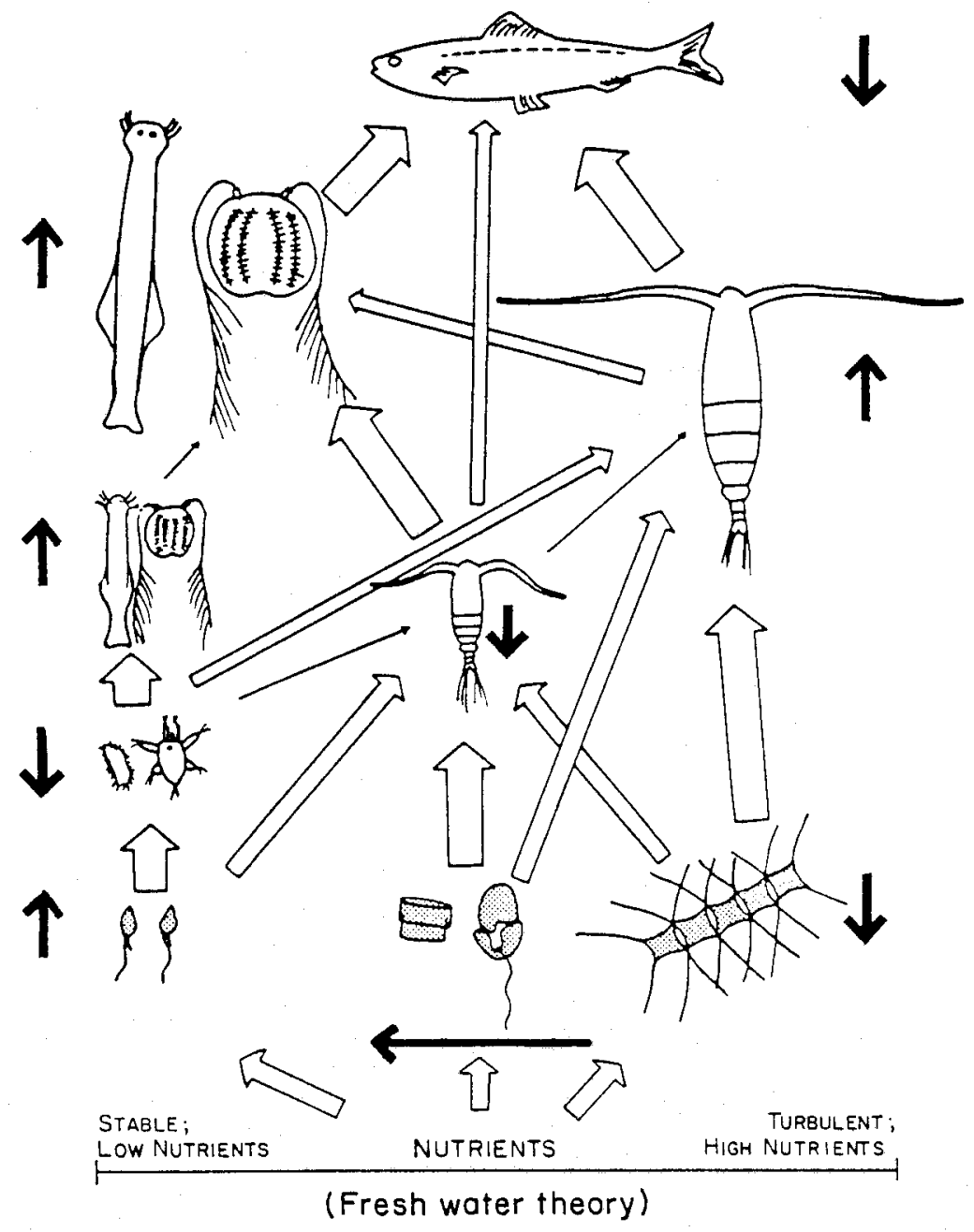

Fig. 2. Feeding relations in a simplified planktonic food web and changes expected from the freshwater theory upon the reduction of visually feeding fish. Phytoplankton shaded. Thin arrows: individual development. Open arrows: feeding relations, with width indicating importance. Closed vertical arrows: expected increase (up) or decrease (down) of concentrations. Horizontal closed arrow: expected shift of phytoplankton size composition (Modified from Landry, 1977)

ism might work in such a way that turbulent water, while supplying nutrients, would favour large-celled algae that in still water tend to settle, which in turn would favour large suspension feeders that are good food for visually-feeding fish (right-hand pathway in Fig. 2). At the same time, the portion of the food web on the left-hand side of Figure 2 would be affected by competition for nutrients among the algal size classes and by the increase in numbers of larvae, or young, of the large suspension feeders. Overall, the animal part of the web would largely have an opportunistic character by being dependent on the well-being of their food resources, which changes seasonally (including the 
annual re-setting of the cycle in spring by the abiotic environment), as well as interannually (see Fig. 3). With bottom-up control, the food web structure would not be drastically affected by the removal of planktivorous fish (top predator in Fig. 2).

In the same year as Landry's paper, Steele \& Frost (1977) argued for top-down control in a food web similar to that in Figure 2. Predation not only reduces the concentration of prey but also tends to be size-selective because most small [large] aquatic animals (small species or juveniles of large ones) cannot handle large [small] food; further, bigger prey tends to be preferred by any species within the size range that can be handled. Overall, predation also alters the structure of the community. Note that in terms of energy flow, nutrient recycling, etc., the predators are much less important than their prey, but exercise their influence through species- and size-selective removal of specimens. One implication of top-down control is that heavy fishing would change the community composition markedly, beyond affecting the immediate prey, and shift a food web as in Figure 2 to the left, toward a sea dominated by small phytoplankton and invertebrate predators. While Steele and Frost's (1977) reasoning is based on an involved mathematical model for the size composition of a temperate plankton community, a large body of experimental work in freshwater that also should apply to the marine realm supports this mechanism (reviews by Carpenter et al., 1991; Likens, 1992, p. 21; a critical compilation by DeMelo et al., 1992). Limnologists, of course, can manipulate their systems, set aside control sites or containers during experiments, and (very important!) can revisit virtually the same manipulated water and specimens, all of which is not possible in the unconfined open sea (for new papers about experimental work in large saltwater containers [mesocosms], see Vanni \& Findlay, 1990; Olsson et al., 1992).

The changes in a planktonic food web upon reduction of visual predators expected from predominate top-down control are also indicated in Figure 2 (mostly based on Koslow, 1983). Unintentionally, this theory was put to the test in the North Sea: between 1965 and 1970 the biomass of herring and mackerel (then the principal copepod-feeding fish) declined by $65-75 \%$ because of overfishing; the herring slumped further until the fishing ban of 1977 to 1982 (cf. Fig. 3, and Bailey \& Steele, 1992). Koslow (1983) noted, however, that the actual changes in the plankton were largely opposite to what would be expected from top-down control: all major zooplankton groups, as well as the largecelled phytoplankton, declined (cf. panels in 2nd row of Fig. 3). As to the reasons, to begin with, it is very difficult to establish cause-and-effect (e. g. bottom-up control in this case) from field observations. Moreover, during the same period in the North Sea, fishing pressure was enhanced on account of new technology and economic forces. Also, pollution generated at sea and contributed to from the land increased, and the climate (temperature, frequency and strength of winds, rain and the resulting river runoff) fluctuated.

Fortunately at this time, the northeastern North Atlantic west of Scotland and Ireland could be used as a control region: the narrow shelf does not promote much fishing on the species at issue, and the change in pollution over the period can be expected to have been much less than in the North Sea (Koslow, 1983). The same kind and same quality of plankton data were at hand through the time series compiled by the Continuous Plankton Recorder Survey (cf. Colebrook, 1986, 1991). Koslow (1983) noted essentially the same decline of plankton in the northeastern North Atlantic as in the North Sea, largely involving even the same species, which points to overriding climatic effects on plankton 

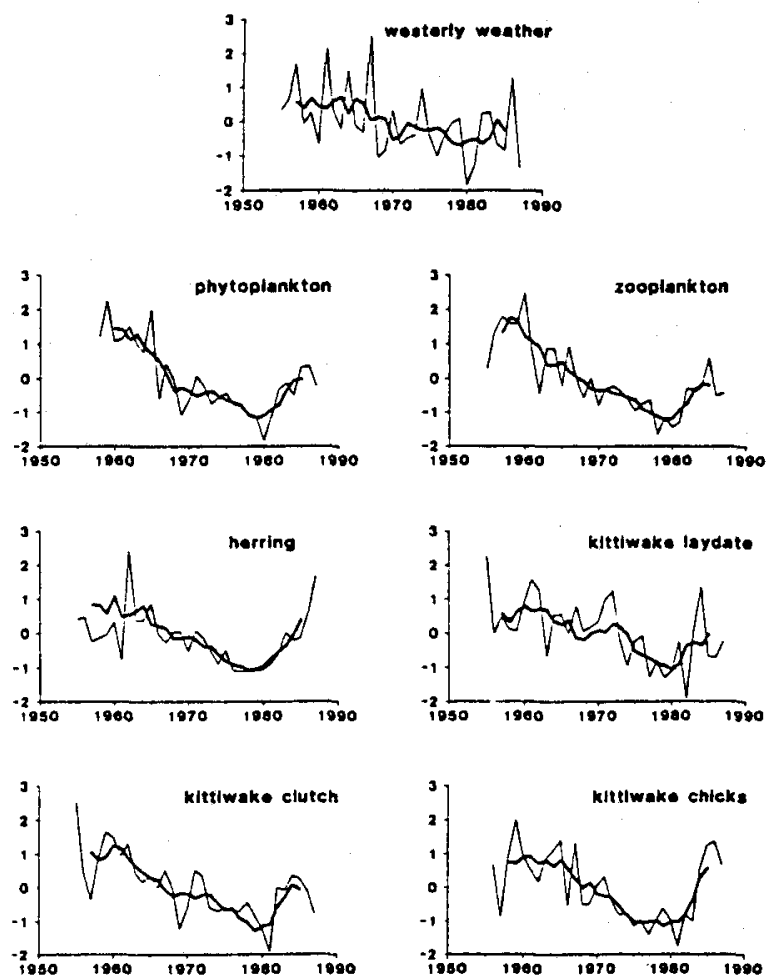

Fig. 3. Standardized values of time series and 5-year running means for frequency of westerly weather, abundance of phytoplankton, zooplankton, and herring, in the northwestern quadrant of the North Sea, and for kittiwake gull laying-date, clutch size, and chick production in a bird colony on the northeast coast of England, from 1955 to 1987 . Ordinates in units of standard deviation from overall means, based on principal component analysis. In absolute terms, the 5-year running means for frequency of westerly weather ranged from 60 to 82 days year $^{-1}$ (From Aebischer et al., 1990, with permission from Nature, London, 347: 753, 25th Oct. 1990.)

abundance. However, why did the gross change in plankton-feeding fish in the North Sea $\mathrm{n}$ ot alter the community composition of the plankton? Was (a) our theory wrong (see Harris, 1985), or (b) the expected biological effect fortuitously compensated for by an opposite effect of pollution, or (c) were the roles of herring and mackerel taken over by another visually-feeding fish that previously had been out-competed?

The question about the validity of our theory ( $a$, above) cannot be answered as yet this fact will be a main theme for the remainder of this paper (see also Steele, 1991). The issue of fortuitous compensation of fishing and pollution effects (b, above) is so vague that any number of hypotheses about the reasons might be advanced. I am afraid that none will be testable, and therefore none should be pursued at the present time (cf. Platt, 1964). Regarding compensatory replacement among visually-feeding fish ( $c$, above), the biomass of sand lance greatly increased, at the time, in the northeastern and the northwestern North Atlantic (Sherman et al., 1981; Fig. 4) so that this explanation (c) might be valid. 


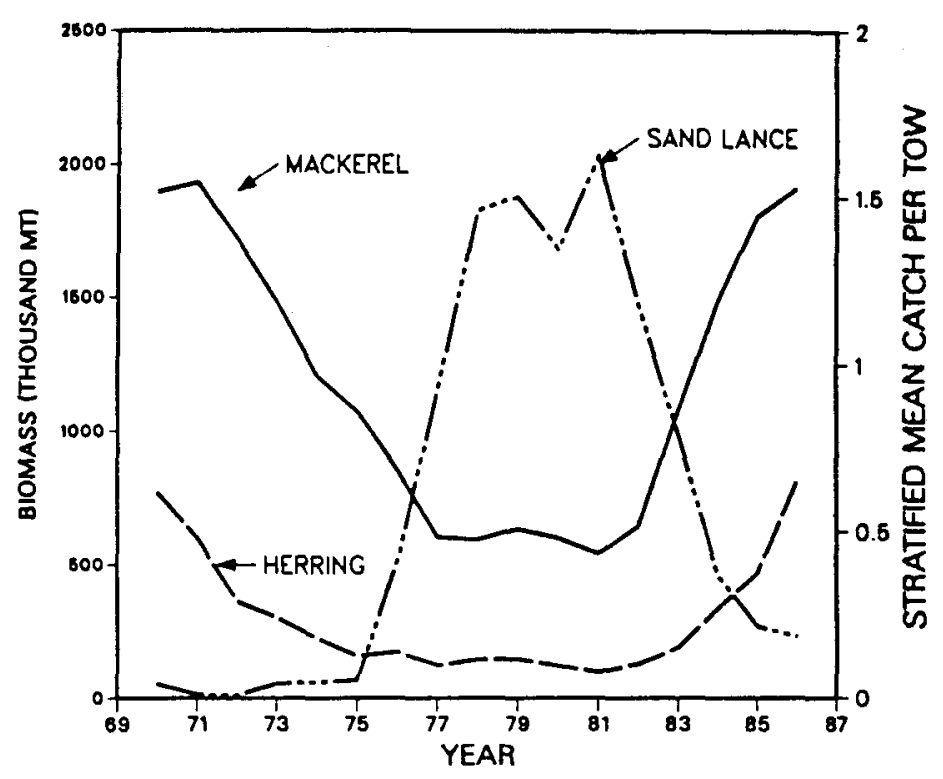

Fig. 4. Trends in biomass of mackerel ( 1 year and older) and herring ( 3 years and older) and catches of sand lance (2 years and older) per unit haul by research vessels, from 1969-1987 off the northeastern United States (from Fogarty et al., 1991, with permission by I. C. E. S., Copenhagen)

Similar changes in sand lance abundance in widely separated areas also point to the major role that natural variation of climate plays, against the background of which we attempt to observe the biological effects of human-caused, unidirectional climate change.

\section{CLIMATE CHANGE AND EFFECTS ON MARINE ORGANISMS}

By way of introduction, the oceanographic mechanisms underlying global climate change will mainly involve the open ocean because of the size of this reservoir for heat, moisture, and gases. Even so, the coastal marine stations will have to play a major role, especially in the biological research that will be needed to answer questions about climate change, as will become apparent later. I note also that planktonic and bottomliving organisms cause organic matter to be permanently buried in sediment, and can potentially remove some anthropogenic $\mathrm{CO}_{2}$ in this fashion, provided that hitherto unused nutrients become available for this pathway. In respect to bottom processes and burial in particular, the generally richer near-shore waters seem to be nearly as important as the vast, open ocean. The issue here is whether global warming will shift the relative importance of the two domains.

Questions about climate change and common marine organisms, feedbacks, and the degree of our understanding of the underlying cause-and-effect relations, are timely: in the next two or three decades, we will have to estimate the effects of greenhouse warming, especially those on human kind, with reasonable accuracy so that timely action can be planned, or shown to be unnecessary. Presently, however, even the physics of the 
atmosphere-ocean-land system is not well-enough understood to calculate with confidence the warming that would result from a given increase in atmospheric $\mathrm{CO}_{2}$. With respect to consequences for the plankton, very likely the direct effects of temperature changes on marine organisms will be less important than changes in physical-oceanographic factors like currents, timing and location of water column stratification, or nutrient supply from below, all of which may lead to wholesale shifts of community distributions. In a given area and, for example, for an individual DMS-emitting species, the effect of a mild warming of the sea surface cannot yet be predicted either, not even in the case when changes of surface currents, etc., are negligible. The main problem is that an enhancement of division rates of one phytoplankton species will propagate through the food web (Figs 1 , 2) via the competition among the phytoplankton and the effects on the animals feeding on them, so that the percentage increase of abundance (if any!) of that species cannot be predicted yet, let alone an expansion or contraction of its geographic range.

The principal point of this chapter is that even mild climatic changes, of the degree that most present, physical calculations predict from greenhouse warming in the next few decades, do measurably affect the plankton. For example, a similarly mild change of weather pattern over western Europe during the course of 33 years is correlated with changes of abundance, at four trophic levels, for a sizeable part of the northwestern North Sea (Fig. 3). Again, an explanation for the correlation cannot be offered as yet (Aebischer et al., 1990). The authors suggest that a direct trophic link between plankton and fish is unlikely; in contrast, herring is an important food for the gulls, prior to breeding. For both connections (zooplankton - fish; herring - birds), the statistical evidence points, at least in part, to independent climate-driven effects on each group of organisms. Also the longterm change of abundance of common zooplankton species in the North Sea and the northeastern North Atlantic during summer, which heavily weights the annual average, has been tied to changes in winter survival (Colebrook, 1986), which is presumably weather-related. Additional observations on zooplankton and phytoplankton in the same area are found in Roff et al. (1988), and on North Sea herring in Bailey \& Steele (1992).

The fluctuations of abundance of other dominant fishes during the same last few decades are also not really understood, for example, the above-mentioned similarity of sand lance abundance changes in the northeastern and northwestern North Atlantic (presumably related to climate variability), or the outburst of gadoids (cod-like fishes) in the North Sea starting in about 1962 (Cushing, 1984; "better recruitment" - yes, certainly, but could we have predicted it?). The other, most impressive, example of climate-induced changes of abundance, involving animals in two oceans and hemispheres, are the recent synchronous increases of the European pilchard and three Pacific sardine species, the Far-eastern, Californian, and Chilean sardines (Kawasaki, 1991; according to this author, the three may be the same species, but the geographic distributions are not connected [disjunct]).

Why do we not understand the relations between climate change and marine organisms? Why can one in a keynote address use as centre-pieces pictures that are almost 70, and 17, years old (Figs 1 and 2, respectively), but not put it all together? Note that the insufficient understanding concerns abundant plankton organisms, as well as fish, by far the best-known and best-sampled group of marine animals. Our understanding is insufficient, in spite of almost 150 years of research in the North Sea (which, with the Baltic, is certainly the best-studied sea in the world), and in spite of the number of 
researchers that has increased approximately exponentially with doubling times of about 30 years (three data points for 100 years at the Biologische Anstalt Helgoland; annual figures for the German Zoological Society [DZG] since 1890 from Geuss \& Querner [1991] as a proxy for a general trend; for $\mathrm{DZG}_{r} \leq 20$ years when the breaks from two wars and emigration during the 1930's are omitted). There is no single answer for the opening question of this paragraph, but that in itself leads to the next one: how can we do better in the future, i.e. in the next 10 to 20 years?

\section{REMARKS ON STRUCTURING ECOSYSTEM RESEARCH}

In spite of the ambitious title of this lecture, no catalogue of proposals for solutions is offered, but the issue will be illustrated by one example. The global problems, which humanity has recently created through technology, together with the continued, inevitable increase in the world's population, are the reasons why the earth, including the seas, will have to become "a managed, wired garden". Relatively more environmental research than is being performed today will therefore be inevitable, but will it suffice to merely add scientists (exponentially?), who will essentially do more of the same, or do we need to add new features to our research mode and organisation? For brevity's sake, I will state my views largely without reference to the literature.

\section{Premisses}

(a) Contributing as biological oceanographers and marine biologists to research on global climate change principally means study of the plankton. (b) The pelagic ecosystem is very complicated. The questions posed by Figures 1 and 2 really apply more or less to the systems in all seas, but they should be answered first for the North Sea and the Baltic: if they cannot be answered in these well-studied areas, then there is little hope for making predictions anywhere about global change that go beyond extrapolations from correlations. (c) A comprehensive treatment of the pelagic domain will have to assume the form of mathematical models: only their attendant rigorous formulations will unambiguously expose gaps in our knowledge and permit testing of predictions beyond the qualitative comparisons of the sort used in Figure 2. (d) Rapid progress towards models of even the simplified kind of Figure 2 (with larvae and juveniles of the principa] animal players and the predators of the fish [top of figure] added), as already stated, is principally hampered by scarcity of data on simple natural history and rates of such mundane processes as rates of development or feeding of quite common planktonic species. In my view, it is entirely unlikely that the necessary data will be accumulated within the next 2-3 decades if we continue with the traditional way of carrying out this research. (e) We also lack ideas (theory) about how the various biological subsystems in the pelagic domain function: for example, whether or not they tend to chaotic behaviour (speaking mathematically) and, if so, what the spatial and temporal scales are. However, Figure 3 and the mentioned temporal pattern of abundances of pilchard and sardines show that chaos does not reign on oceanic and decadal scales. (f) Ecosystem models and their predictions, like any other scientific hypothesis, need to be testable. ( $g$ ) Scientific and sociological changes seem inevitable for the near future, generally not only because of the advance of time, but also because the pending unified labour market of the 
European Community will affect the scientific community. Among other effects, it should lead to more personal mobility, therefore leading to an enhanced exchange of ideas and habits. We should make the best use of such changes.

\section{Scenario for change in approaches}

What might be done, and where? The natural history of the species of interest has to be studied in the sea, and rate measurements also have to be made at laboratories near salt water. Here is the first and continuing task of the marine stations - ships alone will not do; because the saltwater supply of the Biologische Anstalt is open-sea water, the institute continues to be predestined for such work. The necessary measurements could be obtained quickly by simply throwing money at the problem, since the methods of such studies are more or less known. It is not that simple however, even under the best of circumstances, considering the ideas, i. e. the conceptual framework, that are needed for guiding the effort. The entire matter becomes really complicated, once money is not freely available.

As noted, a continuing haphazard accumulation of natural history observations and rate measurements on even the common species will be too slow for permitting a quantitative treatment of the response of food webs as in Figures 1 and 2, by the time it is needed. In my view, the mode of data accumulation needs, instead, to be better structured than has been the case, mainly by agreeing on clear sets of scientific objectives. Granted (1) that the marine stations will have to continue with their service functions to the inland community of scholars and institutions, and $(2)$ that there are not enough funds to do everything that may appear to be promising for an understanding of global change, might we not consider the following as one of several possible a d dition s to our present way of operating:

(a) State as an explicit goal the building, by groups of scientists, of ambitious models of the planktonic ecosystem for geographic regions with a large base of existing knowledge, i. e. natural sub-units of the North Sea and the Baltic. These groups would need to have a broad composition in order to include ideas from adjoining disciplines, and would have to meet for extended periods or even reside for a few years at the same institute. (b) Use the new models to guide some of our future data-collection efforts in field and laboratory, which can in turn suggest what is important for running and testing the models themselves and, hopefully, for predicting ecosystem responses to global change.

The aim of this approach would be to create a tramework of unifying concepts (similar to those of Darwin for contemporary zoology, and recently, to the theory of plate tectonics for geology, albeit on a lesser plane) for making choices for field and laboratory efforts in the proposed ecosystem research. Not all possible objects of research are equally essential, and not all members of plankton communities are equally important for their functioning, so that ways should be sought to facilitate the choices that need to be made in the face of monetary and temporal constraints. Note that once a unifying framework is recognized, it also should inspire cooperation among individual scientists and a willingness to contribute to the common good - but comments on group dynamics are outside the scope of this address.

Of course, reasonably involved food-web models are currently being developed and 
published (see below). The first point I wish to make, however, is that they are usually developed after a cruise or expedition. In any case, most tend to be of little consequence because everybody continues to do his/her own thing after having glanced at the particular paper presenting the results - there is so much to read! Secondly, to my knowledge, groups of marine ecosystem modellers have not met, tackled together the same data set with each of their favourite models, and compared the results. Thirdly, in contrast to, for example, the rapidly progressing fields of biochemistry or genetics and in spite of the above-mentioned mathematical models, the haphazard accumulation of data persists in marine biology because there is no apparent strategy or objective, and because unifying concepts are scarce. To my knowledge, biochemistry and genetics (in part now beginning to be joined in biotechnology) are fast-moving because theory permits anticipation of the outcome of experiments. This, early-on, permits the design of alternative experiments for testing and, if necessary, rejecting hypotheses, thus guiding the further collection of data. The money and positions those fields possess now, in contrast to the 1920's or 1930's, are a consequence of their rapid progress, and not the other way around. Marine biology also must learn from these fields in this respect.

Even a guided programme of natural history observations and rate measurements in a sector of marine biology will certainly require at least a decade, and probably two decades, of concentrated work by many people. Fortunately, most temperate organisms are widely distributed, and therefore the data need not be acquired at a single institute. Further, the initial modelling effort will take several years, because all of the theory is not in hand (e.g. Rothschild, 1988), and because the models will have to be biologically $\mathrm{m} \mathrm{u} \mathrm{ch}$ more involved than the present plankton or multi-species fisheries models; they also will have to address the usually difficult issues of coupling with the temporal and spatial scales of the physical processes. However, I would like to emphasize that it is important for the initial modelling effort to precede the actual, observational or experimental study of the ecosystem, and not follow it, as has too often been the case in the past.

The present status of ecological modelling in the North Sea, and hints regarding data-bases may be seen in the review by Fransz et al. (1991). A cross-section of issues and views on multispecies models in fisheries management, as an example of involved approaches, are available in Daan \& Sissenwine (1991; see also Rothschild, 1991). Reference to studies of chaotic behaviour in planktonic systems may be found in Scheffer (1991), suggestions for future work, especially in the pelagic domain, in Rothschild (1988), and remarks about institutional structure, in Callahan (1991). An interesting perspective was raised by Belsky (1989), i. e. that the 1982 Convention on the Law of the Sea "should be read as mandating an ecosystem approach to ocean management" ( $p$. 450); the Convention is international law that is binding on national governments. His remark was made at a symposium dedicated to ecosystems as geographic categories; but their wise management is not possible without understanding the basics of the functioning of the pelagic ecosystem in the sense used herein.

Major issues to watch when guiding research efforts are (1) to fo c u s research but not direct it (e.g. "Do brown-tide research"), since the latter would soon stifle creativity; (2) not to be afraid of scientific mistakes. These are bound to happen, especially in this kind of experimental approach of model-driven research; (3) with the constraint of funding, to avoid the creation of permanent groups (by adding permanent positions) that initially have a laudable goal, but whose members stay on and on and become intellectu- 
ally stale after the goal has been achieved or become moot. Of course, in return for abandoning sacred ideas about the permanency of all academic jobs, a reward system might be needed that, for example, might be based on publications. Even geniuses sometimes need encouragement!

Leaving aside further details, the principal message I wish to convey is that a way for the development of quantitative theory be found and thus facilitate some planning of intellectual development in marine biology, and not leave it entirely to chance.

Let me return once more to specific tasks of marine stations: models of plankton communities, including sub-models, need to be tested or validated while being developed. In the open sea, however, results of testing that can clearly show a model to be wrong are very difficult to obtain (e.g. uncertainty about eddy diffusion that affects population change in addition to growth and mortality). Also, like in a river but in contrast to a lake, in the sea we cannot ever swim in the same water. However, model sub-units concerned with, for example, population dynamics or mass balances in particular strands of food webs, can (and should) be accurately tested in replicated large sea-water aquaria, perhaps including floating bags of many tens of cubic metres, with organisms of generation times of up to a few weeks (so-called mesocosms). No one so far has experimentally investigated the predictability of the size composition of phytoplankton and grazers in a food web consisting of three pillbox-shaped non-colonial diatoms of markedly different size, grazed upon by two copepod species of markedly different size but otherwise similar (e.g. Calanus and Pseudocalanus spp.), with predation on the nauplii replaced by the removal through the measured overflow of water and that on the large developmental stages by a plankton net. Are we already able to make the measurements necessary for predicting future states of even such a deterministic and, hence, relatively simple system? Does chaos reign? But - if we cannot even model bags, should we ever consider bays?

Finally, looking at the present efforts and successes of physicists who model weather and climate, I emphasize that it is not certain that in the reasonably near future (10-20 years) we will be able to comprehend a web, as in Figure 1, so that the organismic response and their feedback $\left(\mathrm{CO}_{2}\right.$ uptake, DMS release) to climate change can be accurately calculated. It is quite certain, though, that arriving at such comprehension at present is not impossible. Thus, let us take up the challenge!

\section{CLOSING REMARK}

The ships we use are of feminine gender. This holds apparently for the names of institutes (die Biologische Anstalt). What does one say to a lady on her 100th birthday? "Well, Madam, you look GREAT! Apparently, 100 years is nothing nowadays. But if you do worry about your looks, why not go with the scientific fashion, change your make-up a little, and you will easily retain your appeal for another 100 years."

Acknowledgements. I am most grateful to Professor W. Gunkel for having asked me to give this address. While the National Aeronautics and Space Administration supported the preparation of the manuscript (Grant No. NAWG-1007), the travel and attendance at the symposium was provided by the Biologische Anstalt Helgoland. Dr. B. W. Frost made some sceptical but important comments about the content, and Dr. D. P. Henry improved the style of the text. Contribution No. 1957 by the School of Oceanography, University of Washington. 


\section{LITERATURE CITED}

Aebischer, N. J., Coulson, J. C. \& Colebrook, J. M., 1990. Parallel long-term trends across four marine trophic levels and weather. - Nature, Lond. 347, 753-755.

Bailey, R. S. \& Steele, J. H., 1992. North Sea herring fluctuations. In: Climate variability, climate change, and fisheries. Ed. by M. H. Glantz. Cambridge Univ. Press, London, 211-230.

Belsky, M. H., 1989. Development of an ecosystem management regime for large marine ecosystems. In: Biomass yields and geography of large marine ecosystems. Ed. by K. Sherman \& L. M. Alexander. Am. Ass. Adv. Sci., Washington DC 443-459.

Bückmann, A. (Hrsg.), 1959. Die Wiedereröffnung der Biologischen Anstalt Helgoland 1959. Helgoländer wiss. Meeresunters. 7, 1-50.

Callahan, J. T., 1991. Institutional structures. In: Comparative analyses of ecosystems - patterns, mechanisms, and theories. Ed. by J. Cole, G. Lovett \& S. Findlay. Springer, New York, 343-345.

Carpenter, S. R., Frost, T. M., Kitchell, J. F., Kratz, T. K., Schindler, D. W., Shearer, J., Sprules, W. G., Vanni, M. J. \& Zimmerman, A. P., 1991. Patterns of primary production and herbivory in 25 North American lake ecosystems. In: Comparative analyses of ecosystems - patterns, mechanisms, and theories. Ed. by J. Cole, G. Lovett \& S. Findlay. Springer, New York, 67-96.

Charlson, R. J., Lovelock, J. E., Andreae, M. O. \& Warren, S. G., 1987. Oceanic phytoplankton, atmospheric sulphur, cloud albedo and climate. - Nature, Lond. 326, 655-661.

Colebrook, J. M., 1986. Environmental influences on long-term variability in marine plankton. Hydrobiologia 142, 309-325.

Colebrook, J. M., 1991. Continuous plankton records: from seasons to decades in the plankton of the North-east Atlantic. In: Long-term variability of pelagic fish populations and their environment. Ed. by T. Kawasaki, S. Tanaka,Y. Toba \& A. Taniguchi. Pergamon Press, Tokyo, 29-45.

Cushing, D. H., 1984. The gadoid outburst in the North Sea. - J. Cons. int. Explor. Mer. 41, $159-166$.

Daan, N. \& Sissenwine, M. P. (Eds.), 1991. Multispecies models relevant to management of living resources. - ICES mar. Sci. Symp. 193, 1-358.

DeMelo, R., France, R. \& McQueen, D. J., 1992. Biomanipulation: Hit or myth? - Limnol. Oceanogr. $37,192-207$.

Fogarty, M. J., Cohen, E. B., Michaels, W. L. \& Morse, W. M., 1991. Predation and the regulation of sand lance populations: an exploratory analysis. - ICES mar. Sci. Symp. 193, 120-124.

Fransz, H. G., Mommaerts, J. P. \& Radach, G., 1991. Ecological modelling of the North Sea. - Neth. J. Sea Res. 28, 67-140.

Garçon, V. C., Thomas, F., Wong, C. S. \& Munster, J. F., 1992. Gaining insight into the seasonal variability of $\mathrm{CO}_{2}$ at Ocean Station $\mathrm{P}$ using an upper ocean model. - Deep-Sea Res. 39, 921-938.

Geus, J. G. A. \& Querner, H., 1990. Deutsche Zoologische Gesellschaft 1890-1990. Fischer, Stuttgart, $187 \mathrm{pp}$.

Hardy, A. C., 1924. The herring in relation to its animate environment. 1.: The food and feeding habits of the herring with special reference to the east coast of England. - Fishery Invest., Lond. (Ser. 2) 7(3), 1-53.

Hardy, A. C., 1959. The open sea: its natural history. II.: Fish and fisheries. Collins, London, $322 \mathrm{pp}$.

Harris, G. P., 1985. The answer lies in the nesting behaviour. - Freshwater Biol. 15, 375-380.

Heuss, Th., 1940. Anton Dohrn. 2. Aufl. Wunderlich, Tübingen, 448 pp.

Kawasaki, T., 1991. Long-term variability in the pelagic fish populations. In: Long-term variability of pelagic fish populations and their environment. Ed. by T. Kawasaki, S. Tanaka. Y. Toba \& A. Taniguchi. Pergamon Press, Tokyo, 47-60.

Koslow, J. A., 1983. Zooplankton community structure in the North Sea and Northeast Atlantic: development and test of a biological model. - Can. J. Fish. aquat. Sci. 40, 1912-1924.

Landry, M. R., 1977. A review of important concepts in the trophic organization of pelagic ecosystems. - Helgoländer wiss. Meeresunters. 30, 8-17.

Likens, G. E., 1992. The ecosystem approach: its use and abuse. Ecology Institute, Oldendorf, 166 pp.

Longhurst, A. R., 1991. Role of the marine biosphere in the global carbon cycle. - Limnol. Oceanogr. 36, 1507-1526.

Malin, G., Turner, S. M. \& Liss, P.S., 1992. Sulfur: the plankton/climate connection . -J. Phycol. 28 , 590-597. 
Olsson, P., Granéli, E., Carlsson, P. \& Abreu, P., 1992. Structuring of a postspring phytoplankton community manipulation of trophic interactions. - J. exp. mar. Biol. Ecol. 158, 249-266.

Platt, J. R., 1964. Strong inference. - Science, N. Y. 146, 347-353.

Roff, J. C., Middlebrook, K. \& Evans, F., 1988. Long-term variability in North Sea zooplankton off the Northumberland coast: productivity of small copepods and analysis of trophic interactions. - J. mar. biol. Ass. U. K. 68, 143-164.

Rothschild, B. J. (Ed.), 1988. Toward a theory on biological-physical interactions in the world oceans. Kluwer, Dordrecht, $650 \mathrm{pp}$.

Rothschild, B. J., 1991. Multispecies interactions on Georges Bank. - ICES mar. Sci. Symp. 193, 86-92.

Scheffer, M., 1991. Should we expect strange attractors behind plankton dynamics - and if so, should we bother? - J. Plankton Res. 13, 1291-1305.

Sherman, K., Jones, C., Sullivan, L., Smith, W., Berrien, P. \& Ejsymont, L., 1981. Congruent shifts in sand eel abundance in western and eastern North Atlantic ecosystems. - Nature, Lond. 291, 486-489.

Steele, J. H., 1991. Ecological explanations in marine and terrestrial systems. In: Marine biology - its accomplishments and future prospects. Ed. by J. Mauchline \& T. Nemoto. Elsevier, Amsterdam, 101-106.

Steele, J. H. \& Frost, B. W., 1977. The structure of plankton communities. - Phil. Trans. R. Soc. London (Ser. B), 280, 485-534.

Steele, J., Carpenter, S., Cohen, J., Dayton, P. \& Ricklefs, R., 1989. Comparison of terrestrial and marine ecological systems. - Mimeogr. Report of a workshop held in Santa Fe, NM, March 1989 (Nat. Sci. Found., grant No. OCE 8814769).

Vanni, M. J. \& Findlay, D. L., 1990. Trophic cascades and phytoplankton community structure. Ecology 71, 921-937.

Wyatt, T., 1976. Food chains in the sea. In: The ecology of the seas. Ed. by D. H. Cushing \& J. J. Walsh. Saunders, Philadelphia, 341-358. 